\title{
Caballeros mediterráneos de la Edad Media
}

\author{
Pau Cateura Bennasser \\ Universitat de les Illes Balears
}

\begin{abstract}
RESUMEN ABSTRACT
Durante el siglo XIII, en las fronteras de Occidente se conquistan territorios y se organizan sociedades conforme a los principios y mentalidades feudales. La conquista de Mallorca y Ramón Llull resultan ejemplos paradigmáticos de los modelos feudales, dos siglos después de la "revolución".

During century xIII in the borders of the West territories are conquered and feudal societies according to the principles and mentalities organize themselves. The conquest of Majorca and Ramon Llull are paradigmatic example of the feudal models two centuries after the «revolution».
\end{abstract}

PALABRAS CLAVE

Caballeros, Edad Media, Mallorca, Ramón

Llull.
KEY WORDS

Knights, Middle Ages, Majorca, Ramon Llull.

\section{INTRODUCCIÓN}

Con la desaparición del Imperio Romano de Occidente, a fines del siglo $v$, se desvanece la concepción estatal de la defensa. La defensa había sido una cuestión de Estado, que asumía la obligación de pagar las tropas y proporcionarle las armas. Durante el medio milenio posterior, Europa intentó fórmulas de reconstrucción estatal, primero a través de los reinos bárbaros, atrapados algunos de ellos en el espejismo de la continuidad imposible, desplés con el Imperio Carolingio y Otónida.

Pero solamente la revolución feudal, en el entorno del año 1000, acabó cristalizando en un perfil definitivo de organización política, económica y social. Grupos 
de guerreros se imponen al resto de la población, usurpando funciones públicas y generando nuevos reordenamientos del espacio y de los hombres en torno a núcleos y centros fortificados ${ }^{1}$.

Ha nacido una nueva sociedad, la sociedad feudal. Pero el carácter anárquico del nuevo sistema, en sus comienzos y primeros desarrollos, no pasó inadvertido a la Iglesia de la época. La violencia multidireccional de la nueva casta emergente, empezando por la propia violencia en el seno de su propia clase, no sólo iba dirigida a reducir a los campesinos a un status de mano de obra sometida y disciplinada, sino también acomodar jerarquías y propiedades eclesiásticas a sus propios intereses.

Coincidiendo con el triunfo de los nuevos grupos de guerreros, se produce un movimiento de reforma y centralización de la Iglesia, que pronto evolucionará desde la apelación a la independencia a la imposición de la supremacía. Superado el reto de la conflictividad de los poderes que se reclamaban universales, era el momento de abordar el remodelado funcional de la nueva sociedad. Los sistemas bipolares anteriores, laicos y eclesiásticos, libres y esclavos, quedaban obsoletos, de ahi la primeriza y certera clasificación funcional de Adalberón de Laon, proponiendo una división tripartita de la sociedad, los que rezan, los que luchan y los que trabajan. División tripartita pero jerarquizada; en la cúspide los clérigos, los guerreros en una posición subordinada, pero integrados dentro de la mencionada estructura y con una misión a desarrollar, la defensa de la sociedad. Integración y prestigio a cambio de renuncia a una violencia indiscriminada.

Pero la historia posterior del nuevo grupo dirigente sigue debatiéndose, en los siglos $x I$ y XII, en foros contradictorios, presididos por la desestabilización en el seno del grupo y fuera del grupo y por los esfuerzos desarrollados en torno a su asimilación.

Ésta es la época de un amplio abanico de iniciativas en diferentes direcciones.La necesidad de poner bajo control la violencia feudal está en la base de un amplio movimiento, la paz de Dios o paz y tregua en áreas más cercanas, y del manto monacal que envuelve nuevas instituciones, surgidas al calor de la lucha contra los infieles; esto último testimonia el principio de la necesidad de asimilación y de mimetismo respecto a las órdenes religiosas, estableciendo una ritualización de pertenencia al grupo con una simbología deudora de la religiosa.

El lenguaje propio de casta dirigente fue explicitado en dos líneas, una línea profana expresada en literatura de clase, con valores calcados de la mentalidad

Desde la óptica de la historia de las mentalidades, G. DuBY: Los tres órdenes o lo imaginario del feudalismo, Taurus, Madrid, 1992; del mismo autor: Guillermo el mariscal, Alianza Editorial, 1997. Este autor, junto con Jacques Le Goff y Pierre Toubert, sostienen la tesis mutacionista, es decir, la ruptura producida en torno al año mil, cuando grupos de guerreros, aprovechando la falta de autoridad, se imponen a los campesinos. Esta tesis ha sido objetada desde diferentes opticas por Dominique Barthélémy. que sólo aprecia “mutaciones" semánticas sin más transcendencia y por K. F. Werner, y matizada por Jean Flory: La caballeria, Alianza Editorial, Madrid, 2001. 
guerrera, como la literatura épica y amorosa alejada de los estándares de la literatura religiosa dominante, y una línea más subsidiaria de valores religiosos, como los textos sobre el orden de la caballería, la creación de un santoral propio y las mismas producciones literarias dramáticas en torno a estas últimas figuras.

\section{LA CABALLERIA CRISTIANA}

Sant Bernardo afirmaba que la espada espiritual debia ser empuñada por la Iglesia y la espada material para la Iglesia. No hay espacios propios ni intersticios para la espada material, sino pura instrumentación. Este mismo punto de vista fue recreado y profundizado por Ramon Liull en su libro "Llibre de l'orde de la cavalleria", redactado en 1275. El objetivo de Llull fue el de fijar un auténtico código moral de los caballeros, donde milicia y moral cristiana forman un cuerpo indivisible ${ }^{2}$.

En el prólogo de la obra emplea una ingenua pero significativa ficción literaria; un viejo caballero, consciente de su falta de fuerzas para seguir en la carrera de las armas y de su próximo final, decide retirarse y comenzar una nueva vida como ermitaño. Pero el desierto en el que decide retirarse resulta ser un hermoso prado con un gran árbol cargado de fruta y con un manantial de agua clara. Casualmente pasa por este lugar un distinguido escudero en camino hacia la corte para ser armado caballero por el rey; coinciden por consiguiente quien está al principio y quien está al final de la carrera de las armas. El viejo convertido en ermitaño y el escudero conversan sobre la caballería. La escena termina cuando el anciano entrega al escudero un libro que había compuesto para restablecer la devoción y la lealtad, rogándole que lo presentara al rey.

Esta introducción puede parecer una simple ficción llena de ingenuidad pero refleja tanto aspectos personales, la misma opción vital de Llull ${ }^{3}$ y su deseo por dar a conocer su obra a los poderosos de su tiempo, como aspectos sociológicos de su época; en los siglos XII y xIII fueron numerosos los caballeros y personajes prominentes que pedian la dispensa de los deberes matrimoniales para dedicarse a una vida monástica.

El autor mallorquin establece un origen tabuloso de la caballería, pero muy de acuerdo con su visión del mundo; en un momento indeterminado comenzó a prevalecer la enemistad, la deslealtad, la injuria y la falsedad. Para que la justicia regresara, el pueblo fue agrupado en milenares y por cada mil fue elegido uno, considerado el más amable, sabio, leal y fuerte. Pese a la incongruencia de esta

Ramon Llull: Obras literarias (Libro de Caballeria, Blanquerna. Féliz, Poesias). Biblioteca de Autores Cristianos. Madrid, 1948, edición preparada y anotada por Miguel Batllori y Miguel Caldentey.

3 En torno a 1276, la esposa de Llull, Blanca Picany, denunciaba ante el batlle de Mallorca que su marido se desentendia de la administración de sus bienes, debido a que "est in tantum factus contemplativus", solicitando el nombramiento de un administrador (J. N. HILLGARTH: Diplomatari Lul.lià, Universidat de Barcelona-Universitat de les illes Balears, Palma de Mallorca, 2001, doc. n. ${ }^{\circ} 12$, p. 36). 
argumentación, resulta un buen pretexto para el desarrollo de sus ideas sobre los valores morales de la clase dirigente.

Si el esfuerzo de la Iglesia era el de someter el comportamiento de los caballeros a un código moral, la tarea de Llull parece ir más allá; convierte el ritual de ingreso en la caballeria en un acto religioso, en una especie de nuevo sacramento. El dia antes de ser armado caballero, el candidato debe confesarse, ayunar y rezar. La jornada de la investidura debe comenzar con una misa solemne con sermón sobre los diez mandamientos y los siete sacramentos. A continuación del acto religioso y, como una prolongación del mismo, el candidato recibirá arrodillado la espada, reconvertida en simbolo de la castidad y de la justicia, y una bofetada, para que recuerde sus deberes en el futuro.

El nuevo caballero es ahora, tras la ceremonia de ingreso en la orden de la caballería, una especie de clérigo, aunque dedicado a tareas seculares. Sus armas están ahora al servicio de la justicia y defensa de la Iglesia. Llull dedica la parte quinta de su libro, en su integridad, a una operación de sacralización de las armas más significativas. Comienza con la espada que, a semejanza de la cruz, debe vencer a los enemigos de la religión Católica ${ }^{4}$. Después hace una relación de nueve armas más (lanza, yelmo, coraza, gola, calzas de hierro, maza, hacha, escudo y perpunte) con la correspondiente simbologia.

Los arreos de las cabalgaduras también son objeto de interés (espuelas, silla, freno y riendas) como símbolos de virtudes como la diligencia, seguridad, control y ánimo en las decisiones. Finalmente incluye al caballo. Al principio del libro, cuando nos explica el origen de la caballeria, nos demuestra su admiración por este animal, desde ópticas estéticas (la más bella entre las bestias), humanas (la más noble). utilitarias (la más rápida y las más apta) y de clase (la que conviene más al caballero). En suma, el caballo simboliza la nobleza de ánimo, y el caballero resalta su preeminencia sobre los demás hombres.

El "Libre de l'orde de la cavalleria" tuvo una importante repercusión tanto en la Peninsula Ibérica como en Europa. El infante D. Juan Manuel, en el "Libro del cavallero i del escudero" utilizó la obra luliana y dos siglos después, Joanot Martorell en "Tirant lo Blanc" convierte al caballero ermitaño, de la obra luliana, en el noble y anciano Guillem de Varoic, lector de libros como "L'arbre de les Batalles".

La obra luliana sobre la caballería marca una línea de la producción medieval, la caballería desde el punto de vista doctrinal. Pero una amplia oferta de libros, destinado al consumo de cortes y nobles, se difunde por la Europa de los siglos Xill$x v$. Se trata de un árbol frondoso, donde se insertan los libros de táctica militar consultados ahora con interés (procedentes del mundo antiguo como los textos de Valerio Máximo, Flavio Renato Vegecio y Sexto Julio Frontino), una literatura

4 "Y porque la espada es de dos cortes y la caballeria es para mantener la justicia, la cual consiste en dar a cada uno su derecho, por esto la espada significa que el caballero con ella deba mantener la caballería y la justicia» (p.129). 
ritualizadora de los conflictos de honor (las "Lletres de batalla»), de veterinaria (la "practica equorum» de Teodorico Borgognoni, nacido en 1208, asi como las indicaciones contenidas en la Partida II, de Alfonso X) y de caza ("Dancus Rex", "Libre de nudriment e de cura d'ocells", "Arte venandis cum avibus" de 1248 como exponentes iniciales de este tipo de obras) ${ }^{5}$.

\section{CABALLEROS Y ESCUDEROS EN LAS FRONTERAS DE OCCIDENTE}

La prosa moral de Llull expresa un ideal en una época de cambios, cuando la estructura de órdenes debe acomodarse en ciertos niveles a nuevas condiciones socioprofesionales; el mismo, en su isla natal, vivió el proceso de formación de una nueva sociedad, donde elementos burgueses de origen mercantil capturaban posiciones sociales y políticas nada despreciables. Cuando en el año 1249, Jaime I creó el municipio de la isla, puso a su cabeza seis jurados, reservando sólo una de las plazas a los caballeros.

Pese al acceso de las clases populares a cuotas de poder local importantes, la creación del reino de Mallorca está vinculada al mundo de la caballería. Si abrimos, el texto fundacional sobre el reparto del botín, encontraremos vínculos, estructuras y formas de propiedad y concepciones de la defensa propias del feudalismo.

El vínculo feudal es el que informa las relaciones entre el rey y los grandes nobles, poseedores de estados o porciones, con los caballeros asentados en sus distritos jurisdiccionales. Esta misma relación es la que se establece entre el rey y el conquistador de la isla de Ibiza, Guillem de Montgrí.

Los bienes conferidos en feudo se denominan caballerias, asignadas a caballeros y escuderos según módulos territoriales prefijados: 227 hectáreas para los primeros, y la mitad para los escuderos. Estos módulos fueron adaptados, de ahi que en determinadas circunstancias se otorgaran bienes en feudo sobre expiotaciones de 1000 hectáreas a un restringido grupo de "primi milites" ${ }^{6}$. Si la plantilla de caballeros que debian defender la isla de Mallorca no debía ser inferior a los 100 , cabe presuponer que no menos de 34.000 hectáreas de tierras cultivadas fueron concedidas en feudo.

En el período de conquista y primera colonización, las Ordenes Militares adquirieron un papel importante. En la conquista estuvieron presentes el Temple, el Hospital de San Juan, San Jorge de Alfama, Calatrava y Santo Sepulcro. La primera de elias fue configurada como un estado, al estilo de las porciones de los grandes nobles, que a mediados del siglo XIII era titular de 7.648 hectáreas. Las de-

Una relación bibliográfica de las obras sobre caza, en Alfonso XI: Libro de la Monteria, Universidad de Granada, Granada. 1992. estudio y edición crítica por Maria isabel Montoya.

"P. CATEuRa: "La repoblació nobiliaria de Mallorca per Nuno Sans" en XII Congrès d'Histoire de la Couronne d'Aragon, Memoires de la Societé archeologique de Montpellier, tome XVI, Montpellier, 1988 , pp. 99-114. 
más órdenes recibieron patrimonios menores, a título de feudo, pero en conjunto las Ordenes militares dispusieron de una base territorial no inferior a las 10.000 hectáreas ${ }^{7}$.

El absentismo de los grandes nobles que participaron en la conquista (el conde del Rosellón, el conde de Ampurias y el vizconde de Bearn) y la venta de sus bienes en un proceso a lo largo del siglo XIII y principios del siglo XIV, además de la extinción del Temple en 1313, convierten a los caballeros en el exclusivo exponente de la aristocracia de Mallorca.

Desde la conquista los caballeros fueron incorporados a las áreas de poder del reino de Mallorca, ocupando cargos locales de delegación real, lugartenientes reales, "batlles", "veguers" así como guardianes de castillos, mando de flotillas, capitanias de distrito, incluso alguna "batllies" rurales fueron reservadas a caballeros.

Pero la pequeña aristocracia insular en formación, del siglo XIII y principios del siglo XIV, tiene unas características diferentes propias, por lo que cabe distinguir cuatro orientaciones diferentes:

a) El caballero payés: un sector importante del estamento militar mallorquín opta por vivir de forma casi permanente en sus caballerias del interior de la isla. Es posible calcular que un tercio de sus miembros vivian en el campo hasta principios del siglo XIV. Incluso cuando eran designados para algún cargo municipal tenían que ser convocados, bajo imposición de multa, para que se presentaran a las reuniones.

b) El caballero violento: No es una especie muy representativa per hay algunos ejemplos. En 1243-1244 el caballero Bernardo d'Olzet hizo testamento. Una parte importante de sus legados los dedica a compensar injurias inferidas a personas e instituciones. Olzet, por ejemplo participó, junto con otros, en el saqueo y robo de la casa que la orden de Calatrava tenia en la ciudad de Mallorca ${ }^{8}$.

c) El caballero aventurero: La dedicación al corsarismo y la piratería tiene mucha relación con la milícia, aunque con una ventaja evidente: las ganancias por las capturas son muy superiores a los rendimientos de la tierra. Durante el siglo XIII destaca Berenguer de Montcada, protagonista de numerosas actuaciones corsarias, incluso claramente piráticas, contra musulmanes y contra mercaderes italianos ${ }^{9}$. En el siglo XIV se distingue Pere

7 P. Cateura: «Sobre las Ordenes Militares en la repoblación de Mallorca" en Actas das II Jornadas Luso-Espanholas de História Medieval, Vol. IV, Porto, 1990, pp. 3-25. El Temple recibió 122 explotaciones agrarias en tanto el Hospital de San Juan sólo 10 y las demás 2 respectivamente

${ }^{8}$ P. Mora i L. Andrinal: “Diplomatari del monestir de santa Maria de La Real”, I (1232-1360), Palma de Mallorca, 1982, pp. 243-247

"A mediados del sigio XIII realiza una gran actividad corsaria, en viajes "ad Yspaniam" en su nave llamada San Juan, con asaltos incluidos a naves mercantes italianas como el "bucio" de ser Assaldo Sardina, en 1247 (ARM, ECR-343, fol. 187 r.). 
de Tornamira que en 1332 comandaba una flotilla de dos galeras y dos cocas. Contratado por los Jurados de Mallorca para perjudicar a los genoveses realizó actuaciones indiscriminadas contra todo tipo de embarcación, de amigos o enemigos. Sus actuaciones provocaron costosas indemnizaciones a mercaderes venecianos y franceses.

d) El caballero gestor: Desde los inicios de la administración catalana algunos caballeros optan por una carrera administrativa. Pasan a vivir de forma casi permanente en la capital de la isla.Se trata de un reducido grupo de caballeros en el entorno del infante Jaime, heredero de Jaime ${ }^{10}$. Con la creación de la Corona de Mallorca, en 1276, las oportunidades de cargos se incrementaron. Por otra parte, en la primera mitad eel siglo xIV se producen algunos cambios significativos en la composición de la estructura del estamento militar de Mallorca, con el establecimiento de algunos caballeros roselloneses y de familiares reales.

A partir de fines del siglo xIV la crisis económica y la conflictividad social que vive el campo mallorquín, especialmente a partir de 1391, provocará que la mayor parte de caballeros pasen a residir en la capital. A partir de esta época comienza un nuevo proceso caracterizado por la promoción social de foráneos, notarios y mercaderes hacia el caballerato.

\section{EL EJERCICIO DE LAS ARMAS}

En las pinturas murales del Palacio Mayor de Barcelona, de fines del siglo Xill, está representada la conquista de Mallorca. Las escenas conservadas nos permiten contemplar un ejército feudal, integrado por la caballería y la infantería ligera. Los caballeros van protegidos con cota de mallas y perpunte, la cabeza y el cuello con capacete y almófar y las piernas con grevas o calzas de malla. Llevan solamente tres tipos de armas, las espadas, las lanzas y los escudos. Finalmente los caballos llevan protección en la cabeza, con el testero, y en el cuerpo.

Los peones estan divididos en dos secciones, según las armas; una sección de ballesteros, que también llevan espadas, y una sección dotada con lanzas cortas, espadas y escudos. Tanto unos como otros llevan protecciones corporales muy ligeras como los perpuntes, en lugar de cota de mallas que dificultaría la movili$\operatorname{dad}^{11}$.

10 En este periodo el más destacado fue Arias Ibáñez quien realizo todo el reccorrido por la administración local, como «batlle», como "veguer», alcaide de castillos de Alaró y Pollensa y también prestamista del infante Jaime.

1. Sobre el armamento de los caballeros el estudio clásico sigue siendo el de MARTI DE RIQUER: L'arnès del cavaller. Armes i armadures catalanes medievals, Esplugues de Llobregat, 1968. Tamnién A. 1. Alomar: L'armament i la defensa a la Mallorca medieval, Govern Balear, Palma de Mallorca, 1995. 
Éstas son las armas típicas de los ejércitos del siglo xIII; lo que interesaba era asegurar la movilidad del cuerpo al precio de una cierta desprotección del mismo; en efecto, la parte frontal de la cabeza de los caballeros estaba destapada, por lo que ofrecia un buen blanco, pero esta exposición era fruto de una decisión meditada entre protección y control visual del enemigo.

El tipo de armas mencionadas nos informan sobre la forma de combatir. Lanzas, dardos y ballestas permiten un primer ablandamiento del enemigo; después, cuando estaban agotadas o rotas, se pasaba a la lucha cuerpo a cuerpo con las espadas.

Armas y técnicas de combate son transplantados a Mallorca: La plantilla de cien caballeros, establecida en 1230 , es bien indicadora del sentido de continuidad social respecto al Pricipado. Otra cuestión era si dicha plantilla era suficiente para una defensa eficaz de la isla. Pero la creación de un mayor número de feudos no era posible tanto por los compromisos contraídos como por los márgenes de beneficio, por rentas y diezmos, que el rey y los grandes nobles no estaban dispuestos a ceder y por las mismas limitaciones del lento proceso de ocupación del territorio.

Quince años después de la conquista existen todavía porciones señoriales, en las que sólo una cuarta parte de las mismas está cultivada y explotada. La gente se radica en la capital de la isla y en su entorno.

Dentro de estos desequilibrios se encuentra la falta de animales para cabalgar. Caballos y otros animales capturados a los musulmanes, en 1230, debieron ser vendidos en gran parte fuera de la isla. Formaban parte del botín que fue subastado después de ocupada Medina Mayurqa. El resultado fue que el precio de caballos y animales de labranza fue prohibitivo durante muchos años. En 1247 fue vendido el feudo del caballero Lope Ximénez de Luésia. En protocolo aparte fueron vendidos bienes semovientes como tres caballos y tres potros por el precio de casi 1300 sueldos $^{12}$. En estos mismos años el precio de una mula era de 300 sueldos. Estos precios adquieren toda su importancia si los comparamos con el precio de casas rurales, 80 sueldos, o salarios de oficiales como alcaides de castillos (7001000 sueldos anuales).

Como vemos los caballos, parte esencial del equipo de una caballero, eran muy costosos. También el equipo de armas ofensivas y defensivas del caballero. En 1245 un particular presentó como garantía de pago de un préstamo, dos escudos y dos sillas de montar; la deuda era por valor de 80 sueldos.

Por un inventario de los bienes de 1282, conocemos los elementos del arnés de los caballeros del Doscientos:

a) Armas defensivas: cuatro escudos, un perpunte, dos yelmos, dos bacinetes, unas hombreras, unas calzas de hierro, además de camisas, grevas, quijotes y una correa.

12 ARM, ECR-343, fol. $169 \mathrm{v}$ 
b) Armas ofensivas: dos lanzas "cum forro", dos astas, dos mazas, tres espadas, cuatro bordones, un cuchillo de plata con vaina del mismo metal, otro cuchillo.

c) Protecciones del caballo: unas cubiertas de caballo, un testero y unos "sobresenyals» (tela con la divisa heráldica del caballero).

d) Arneses del caballo: dos sillas de caballo, una silla de rocin, tres sillas de mula, dos pares de espuelas viejas, cinco pares de espuelas doradas.

Estas y otras armas integraban el equipo necesario para un caballero ${ }^{13}$. Por otra parte era frecuente, que los caballeros que residian en la ciudad dispusieran también de armas en sus alquerias ${ }^{14}$.

Un equipo tan caro determinaba que los caballeros debieran complementar sus ingresos habituales, de rentas y parte de los diezmos, con otros expedientes. En 1329 se calculaba que cada caballero armado necesitaba una renta anual mínima de 1000 sueldos ${ }^{15}$. Los caballeros que no disponían de un feudo o no disponían de rentas suficientes recibian pensiones complementarias, a cargo del erario real, de 500 sueldos anuales, además de incorporarse a la bolsa de cargos que les estaba reservada, como he señalado anteriormente.

El equipo de los caballeros fue evolucionando a lo largo del siglo xIV hacia un incremento y diversificación de las armas ofensivas y defensivas de hierro. El armamento defensivo evoluciona hacia un blindaje total del cuerpo, de la cota de mallas se pasa a la incorporación de placas de metal y finalmente a piezas de metal rígidas, para el tronco, y articuladas para las extremidades. Cuello y cabeza eran protegidos por piezas de hojalata o malla y por cascos de cuero, los más sencillos, y de hierro y acero. Diferentes tipos de casco permiten una protección del cráneo completa (yelmo, celada) o parcial (bacineta). Los escudos que emplea la caballería disminuyen de tamaño a medida que aumenta la protección corporal de los jinetes.

Durante los siglos XIV y $x \mathrm{~V}$ las espadas se hacen más largas y polivalentes; cuchillos y dagas complementan las espadas. Las lanzas son también alargadas y adaptadas al combate entre caballeros, a la agresión y desarme de los jinetes y a los combates en el mar. Arcos y ballestas son perfeccionados en su potencia de tiro y su precisión.

ARM, ECR-348, fol. $360 \mathrm{r}$ : Item. IV escuts et III bresals, item ill estenas munteras, item II lanceas cum ferro et II astas et III lancers, item II masas, item II seles de caballo et unam de runcino veterem, item IV sellas muiars, item $V$ tirns, inter quos sunt II de senyal, item II morses, item II ampels de ferro et II bacinets, item I perpunt et If capels d'armar, item quasdam espatleras, item 111 enses, item IV bordons, item quasdam cohopertas de caballo et quasdam caligas ferri et lill camisols (...) item unam testeram de cotono, item quasdam gamberes, item duo paria de sperons veyls.

14 Al hacerse inventario de los bienes de la viuda del caballero Guillem de Montegiscard, en 13 misma fecha, se mencionan dos lanzas y una ballesta.

$15 \mathrm{~J}$. ViCH y J. MuntaneR: Documenta regni Maioricarum (miscelánea de docimentos), Palma de Mallorca, 1945, doc. n. 130 , p. 145. Esta fue la renta asignada por Jaime Ill al caballero Arnau de Cardellac, en 1329 , por servir 5 caballos armados 
La protección cada vez más exhaustiva del caballero tiene costos significativos en cuanto a su movilidad, visibilidad y audición. Los movimientos ágiles de la caballeria ligera de otros tiempos son reemplazados por movimientos más lentos y compactos de la caballería pesada. Un casco completo como el yelmo permitía una reducida visibilidad y audición, de ahí los problemas de orientación del jinete. Estos factores determinaban que su blindaje corporal los convirtiera en blancos más bien estáticos, en inferioridad de condiciones frente a las armas arrojadizas, pudiendo ser desestabilizados por las lanzas dotadas de dispositivos para desarmar $y$ derribar a los jinetes.

Pero detrás de las armas están las personas, su destreza y su coraje. Ramón Llull exalta el coraje de los caballeros combatientes, pero recomienda que a la audacia unan el cálculo. El caballero no debe temer herir al enemigo, porque si tiene miedo se coloca a un rango inferior al del caballo, que es bestia y no está dotado de raciocinio.

El valor personal afecta al honor y reputación del caballero, a un sentimiento exaltado de autoestima. La fidelidad reduce aquel sentimiento y lo circunscribe a una persona o institución. Durante la época de los reyes de Mallorca los caballeros pasaron por duras pruebas de valor y de fidelidad. Primero, cuando en el año 1285 Jaime II de Mallorca fue despojado de las islas; después, en 1343 cuando el reino insular fue incorporado a la Corona de Aragón.

La reposición del honor fue una dura prueba para determinados personajes de la época. En 1323, el caballero Huguet de Totzó fue designado almirante de la flota mallorquina que debía participar en la conquista de Cerdeña. Por razones de grave enfermedad, sobrevenida durante las operaciones, decidió abandonar su cargo. No fue nada fácil la reivindicación de su fama. Diez años después de los hechos todavia luchaba por un reconocimiento oficial que justificara sus actuaciones y reivindicara su honor.

Armas y valor personal eran poca cosa sin un adecuado entrenamiento físico. Todo ello implicaba un conocimiento del mundo del caballo, desde la doma a sus cuidados, desde aprender a cabalgar al manejo de las armas. Todo ello implicaba ejercicio y práctica. Por ello nada mejor que juntar oficio y esparcimiento. Un autor de principios del siglo XVII, en plena decadencia del oficio de caballeria, todavia recomendaba a los caballeros salir dos o tres días a la semana al campo, acompañados de un mentor que le corrigiera los defectos tanto en el cabalgar como en el manejo de las armas.

Un complemento imprescindible de los ejercicios anteriores era la caza. La actividad cinegética constituia un buen simulacro de combate. Presuponía, como en la guerra real, un buen dominio del caballo, habilidad y cálculo, sin el coste de un contacto físico. Perros, halcones y azores forman parte del equipo cinegético del caballero; éste les dirige, coordina y les hace converger para su propia finalidad. Todos los caballeros de los últimos siglos medievales tienen en su casa perros y 
halcones; algunos son tan estimados que figuran en los testamentos como piezas significativas del patrimonio. No es infrecuente que los reyes aparten de sus concesiones de tierras los nidos de halcones y otras aves rapaces, reservándose su explotación.

Pero el más fundamental simulacro de la guerra eran las justas o torneos. Estas reuniones lúdicas estaban sometidas a un ritual riguroso, pactado previamente entre las partes; en este paquete entraban los tipos y características de las armas, los ejercicios a realizar y los integrantes de cada tipo de ejercicio. De ahí la gran variedad de estas maniobras, combates a pie y a caballo, individuales y colectivos y simples ejercicios de destreza como tirar al tablado. Estas reuniones, que podian durar días enteros, eran jornadas de gloria para los caballeros que se presentaban con sus mejores vestidos y emblemas, las armas más relucientes y más ricas y la comitiva de escuderos más numerosa, en un ambiente de competición que, a veces, provocaba ciertos recalentamientos del ambiente.

Castillos, torres y caballería feudal fueron derribados por los avances de la pirobaistica introducida a fines de la Edad Media, pero el prestigio de una clase social que, a partir de ahora deberá incorporar nuevos referentes, permanece sin discusión durante largo tiempo; terminaba una época heroica y empezaba una época cortesana. 